\title{
BIA SABIÁ EM “O PESSOAL É POLÍTICO”: (RE)INVENÇÃO DO POLÍTICO NO HUMOR GRÁFICO FEMINISTA DE CIÇA (NÓS MULHERES, 1976-1978)
}

\author{
Cintia Lima Crescêncio ${ }^{1}$
}

\begin{abstract}
Resumo: Uma das principais expressões do feminismo brasileiro na década de 1970 foi a imprensa. Diferentes grupos feministas criaram periódicos que hoje são valiosas fontes para o conhecimento da história do Brasil. Nesses jornais um fenômeno recorrente é o humor gráfico com perspectiva feminista que, a partir das pautas do feminismo, elaborou críticas humoradas às estruturas e instituições responsáveis pela desigualdade entre homens e mulheres. Nós Mulheres, fundado em 1976, foi um dos primeiros jornais a lançar mão do humor gráfico como ferramenta de reflexão. O jornal, que defendia um feminismo autônomo, publicou em seus números tirinhas da cartunista Ciça, protagonizadas pela personagem Bia Sabiá, que problematizavam, através do tema trabalho doméstico, a relação entre privado e público, pessoal e político. Diante do exposto, o objetivo do presente artigo é refletir sobre a (re)invenção do político - e do humor político - no humor gráfico feminista de Ciça à luz do mote do feminismo "o pessoal é político".
\end{abstract}

Palavras-Chave: Periódicos; Privado; Público; Político; Humor Gráfico Feminista.

\section{BIA SABIÁ IN "PERSONAL IS POLITICAL": POLITICAL (RE)INVENTION IN FEMINIST GRAPHIC HUMOR BY CIÇA (NÓS MULHERES, 1976-1978)}

\begin{abstract}
One of the main expressions of Brazilian feminism in the 1970s was the press. Different feminist groups created newspapers that, nowadays, are valuable sources to knowing Brazilian history. In these newspapers a recurrent phenomenon is graphic humor with feminist perspective that, from feminist demands, elaborated humorous critics to structures and institutions responsible for inequalities between men and women. Nós Mulheres (We Women), founded in 1976, was one of the first newspapers to use graphic humor as tool for reflection. The newspaper, that defended an autonomous feminism, published in its editions comic strips from the cartoonist Ciça, starred by the character Bia Sabiá, that question, through the theme of domestic labor, the relationship between private and public, personal and political. Wherefore, the goal of this article is to reflect about the (re)invention of political - and of political humor - in feminist graphic humor by Ciça exploring the motto of feminism "personal is political".
\end{abstract}

Keywords: Newspapers; Private; Public; Political; Feminist Graphic Humor.

\section{BIA SABIÁ EN "EL PERSONAL ES POLÍTICO": (RE) INVENCIÓN DEL POLÍTICO EN EL HUMOR GRÁFICO FEMENINO DE CIÇA (NÓS MULHERES, 1976-1978)}

Resumen: Una de las principales expresiones del feminismo brasileño en la década de 1970 fue la prensa. Diferentes grupos feministas crearon periódicos que hoy son valiosas fuentes

\footnotetext{
${ }^{1}$ Doutora em História pela Universidade Federal de Santa Catarina - UFSC. Professora do curso de História da Universidade Federal do Mato Grosso do Sul - UFMS. Realiza estágio pós-doutoral na Universidade Presbiteriana Mackenzie, no Programa de Pós-Graduação em Educação, Arte e História da Cultura.
} 
para el conocimiento de la historia de Brasil. En estos periódicos un fenómeno recurrente es el humor gráfico con perspectiva feminista que, a partir de las pautas del feminismo, elaboró críticas humoradas a las estructuras e instituciones responsables de la desigualdad entre hombres y mujeres. Nós mulheres, fundado en 1976, fue uno de los primeros periódicos a hacer el humor gráfico como herramienta de reflexión. El diario, que defendía un feminismo autónomo, publicó en sus números tiritas de la cartulista Ciça, protagonizadas por el personaje Bia Sabiá, que problematizaban, a través del tema del trabajo doméstico, la relación entre privado y público, personal y político. Ante el expuesto, el objetivo del presente artículo es reflexionar sobre la (re) invención del político - y del humor politico - en el humor gráfico feminista de Ciça a la luz del mote del feminismo "el personal es político".

Palabras clave: Periódicos; privada; pública; política; Humor Gráfico Feminista.

\section{INTRODUÇÃO}

O humor político é frequentemente compreendido como o humor dedicado a rir da política institucional, notadamente protagonizada por homens - presidentes, monarcas, deputados, ministros - ou eventos considerados importantes - abolição, eleições, promulgação de leis, guerras, corrupção. Nessa premissa o humor gráfico - charges, tirinhas², caricaturas, cartum, hqs - que debate temas considerados "menores" não poderia ser considerado político. Muitas definições de humor político, nesse sentido, esvaziam o teor político do humor gráfico que discute racismo, misoginia, homofobia, preconceito.

Baseando-se na ideia de que o humor é uma arma contra a autoridade, Arthur Power Dudden, referindo-se à realidade política estadunidense e a exploração do riso para ridicularizá-la, aponta a existência de um humor cujo alvo primordial é a política institucional (1987, p. 50-51). Henfil, importante figura do humor gráfico brasileiro e com um olhar alargado para o humor político, em entrevista à Tarik de Souza, destacou que esse humor é uma arma importante e que sua fundação não pode ser baseada no preconceito (2014, p. 93). Ricky Godwin, defendendo o periódico O Pasquim como bastião do humor político, ressalta que o teor político do humor do jornal não pode ser negado (2011, p. 551), mesmo que Rachel Soihet (2007) aponte que a misoginia, o anti-feminismo, o racismo e a homofobia da patota possam ser considerados elementos de suspensão da própria ideia de humor político, como bem nos aponta Henfil.

\footnotetext{
${ }^{2}$ Pesquisadores da área têm recomendado o uso da expressão tira cômica em substituição ao termo tirinha, uma vez que a segunda insinuaria certa infantilização de tal produção, ocasionando um certo esvaziamento político e social de seu conteúdo. Contudo, neste artigo mantenho a expressão tirinha em consonância com a autora das tiras aqui analisadas, cartunista respeitada que há décadas produz tirinhas, como ela as nomeia, para um público adulto.
} 
Tendo tais definições sobre humor político como basilares para o próprio debate sobre humor, este texto tem como objetivo elaborar uma reflexão sobre as possibilidades de (re)invenção da ideia do político a partir do humor gráfico feminista, notadamente tirinhas produzidas por Ciça e publicadas entre os anos 1976 e 1978 no jornal feminista brasileiro Nós Mulheres. Superando as definições convencionais de humor político e discutindo o contexto feminista do período, nas próximas páginas pretendo destacar as múltiplas possibilidades do humor e do político nos traços e jogos de palavras de um humor gráfico produzido com perspectiva feminista e baseado na contestação da dicotomia privado/público, pessoal/político.

A emergência do feminismo durante os anos 1960 teve como um dos motes principais a máxima "o pessoal é político"3. A inversão do modelo "político" vigente foi, portanto, uma palavra de ordem para um movimento que, ao identificar as consideradas questões de mulheres sendo renegadas ao privado, passou a apontar as práticas de poder por trás de argumentos que relegavam ao âmbito do pessoal temas de interesse das mulheres. Para Eleni Varikas o privado doméstico precisa ser observado em duas perspectivas: como produto da ação humana e como produto de uma relação de força (1996, p. 63). Nesse sentido, estabelecer uma relação entre o humor político, a ideia de político e "o pessoal é politico" feminista é tarefa crucial para análise do humor gráfico de Ciça.

Controle de natalidade, legalização do aborto, prazer e sexualidade, maternidade, trabalho doméstico e muitos outros temas passaram a ser alvo de uma discussão que não apenas trazia ao público o que era considerado privado, como também visibilizava o conteúdo político de tais assuntos. O Brasil, mesmo vivendo uma ditadura enquanto mulheres ao redor do mundo organizavam-se em torno de reivindicações feministas, não esteve alheio aos desafios de desestabilização das fronteiras entre o privado e o público, ou ainda, entre o pessoal e o político. Tal mote, por aqui, conquistou força já nos anos 1970 e uma de suas principais formas de expressão foi através da imprensa feminista e, ainda, do humor gráfico feminista por meio da problematização de um dos temas mais debatidos pelos movimentos feministas organizados do período: o trabalho doméstico. A discussão sobre trabalho doméstico atravessava todo o conteúdo de jornais como Brasil Mulher, Nós Mulheres e

\footnotetext{
${ }^{3}$ A história do feminismo costuma ser dividida em dois momentos chamados de "ondas" pela historiografia especializada. A primeira onda faz referência à luta pelo voto e por direitos civis do final do século XIX e início do século XX. A segunda onda tem como mote a expressão "o pessoal é político" que inspirou diferentes movimentos ao redor do mundo, com pautas que defendiam o direito das mulheres ao corpo, ao prazer, ao controle da natalidade. Há pesquisas que, atualmente, apontam a existência de uma terceira e quarta onda.
} 
Mulherio $^{4}$, sendo pauta de matérias, entrevistas, capas, manifestos e um dos temas mais recorrentes no humor gráfico.

No Brasil Mulher, jornal publicado entre 1975 e 1980, as discussões feministas fazendo uso do humor são mais tímidas, uma vez que o jornal emergiu com intenso vínculo com as esquerdas e muito adequado aos modelos de imprensa alternativa da época, em que a seriedade era voga. Isso não significa que o jornal não fizesse uso de charges e cartuns e, eventualmente, tirinhas. Em 19 números (sendo dois especiais), o jornal publicou 55 charges, cartuns e tirinhas. A especificidade reside no fato dessa arte gráfica fazer pouco uso do recurso do humor, além de ter como autores uma maiora esmagadora de homens, com temáticas que problematizavam principalmente temas de interesse das esquerdas e não do feminismo. Já o Nós Mulheres foi criado em 1976 por mulheres exiladas, em sua maioria, e apesar da identificação com as esquerdas, ele emergiu com uma promessa de leveza no debate sobre feminismo. Até seu fim, em 1978, foram publicadas oito edições que contavam com 22 charges/tirinhas. O jornal chegou a publicar uma coluna de humor no número 4, 5 e 6 de 1977. Mulherio teve uma vida ainda mais extensa. Tendo sido criado pela Fundação Carlos Chagas e contando com vasto financiamento, o jornal circulou entre 1981 e 1988. Em suas 38 edições foram publicadas 103 charges e tirinhas.

Nessas dezenas de charges e tirinhas uma cartunista que se destaca é Cecília Whitaker Vicente de Azevedo Alves, mais conhecida como Ciça, uma das mulheres cartunistas mais conhecidas do país. No Brasil Mulher ela assinou uma tirinha, no Nós Mulheres ela assinou cinco, quatro delas versando sobre trabalho doméstico - tema foco deste artigo - e uma sobre controle de natalidade, no Mulherio a cartunista assinou quatro tirinhas. Levando em consideração que Ciça foi responsável por quase $25 \%$ das tirinhas publicadas no Nós Mulheres, todas protagonizadas pela personagem Bia Sabiá, justifico a escolha das tirinhas publicadas nesse jornal para a problematização da ideia convencional de humor político. Ciça, através de Bia Sabiá, faz um exercício de (re)invenção do humor político, tomando o mote "o pessoal é político" como elemento de suspensão da própria ideia de humor político. Além disso, vale reforçar que o feminismo autônomo proposto pela equipe do Nós Mulheres também é elemento importante, uma vez que, com essa perspectiva de feminismo, ele busca

\footnotetext{
${ }^{4}$ Esses três jornais são citados como fundamentais na divulgação de humor gráfico com perspectiva feminista, no entanto é importante referenciar que o período entre 1970 e 1980 viu emergir uma vasta imprensa feminista. De acordo com Elizabeth Cardoso (2004) a imprensa feminista pós-1974 era protagonizada por, no mínimo, 75 jornais.
} 
uma articulação mais evidente com a ideia de que "o pessoal é político", afastando-se de organizações e partidos de esquerda e distanciando-se da academia.

Para elaborar tal reflexão, este artigo pretende analisar as tirinhas publicadas por Ciça no jornal Nós Mulheres entre os anos de 1976 e 1978, à luz dos feminismos do período e tendo como base as discussões sobre humor e sobre humor gráfico. A maioria das tirinhas assinadas por Ciça no jornal tem como mote o trabalho doméstico, tema extremamente rico para o debate sobre política e espaço privado, uma vez que, em muitos casos, o trabalho doméstico sequer é considerado trabalho em função de seu caráter reprodutivo e não produtivo, privado e não público.

O texto está dividido em duas partes: na primeira apresento o jornal Nós Mulheres como uma das formas de expressão do feminismo no Brasil, a partir do mote "o pessoal é político"; na segunda exploro a ideia de humor gráfico feminista como forma de (re)inventar o político e, consequentemente, o humor político por meio da produção gráfica humorística de Ciça.

\section{NÓS MULHERES E O FEMINISMO NO BRASIL}

Em junho de 1976 foi publicado o Nós Mulheres número 1. Com uma capa vibrante em que mulheres diversas foram representadas, o editorial, logo na primeira página, dedicouse a listar as opressões experenciadas por mulheres diferentes nos mais variados espaços: ser dona de casa, ser mãe, ser trabalhadora, ser responsável pela manutenção da família, receber menores salários, ter dupla jornada. Chama os homens a compartilharem da luta por uma sociedade mais justa e agradece o financiamento de Ruth Escobar para a produção do primeiro número do jornal. O texto, que ocupa metade da página, divide espaço com uma tirinha protagonizada por conhecido personagem criado por Ciça, Bia Sabiá. 


\section{Figura 1}

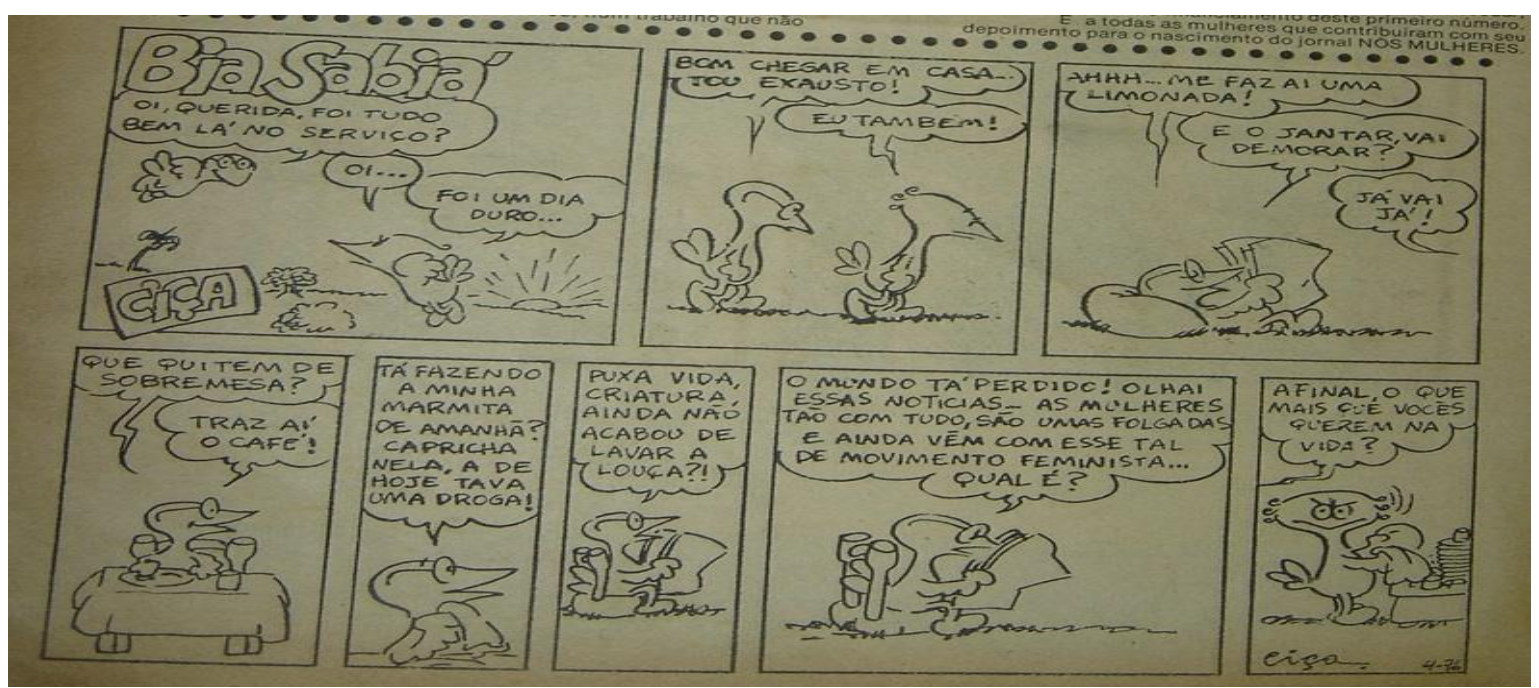

Fonte: CIÇA. Nós Mulheres. São Paulo, junho de 1976, Número 1, p. $2^{5}$.

$\mathrm{Na}$ tirinha, que dialoga diretamente com o editorial, Bia Sabiá, personagem criado especialmente para as publicações feministas, contracena com seu companheiro Heitor. Após uma longa jornada de trabalho, ambos chegam em casa e relatam o cansaço e a alegria da chegada. Na sequência, uma Bia Sabiá invisível e silenciosa é retratada. Heitor, sempre confortavelmente acomodado, tem sede, fome, precisa de sua sobremesa e do café. O simpático pássaro também quer a companhia de Bia que dedica tempo demais para lavar a louça. Na leitura das notícias do jornal ele constata a existência de um movimento feminista e esbraveja: “Afinal, o que mais que vocês querem da vida?". Bia, que havia desaparecido da imagem enquanto Heitor era o protagonista sedento, esfomeado e solitário, aparece no último quadro lavando louças e com semblante revoltado. A tirinha, utilizando animais como personagens e explorando a contradição de Heitor - mas também de todos os homens - trata com humor da dupla jornada e da total falta de consciência do companheiro de Bia. Ao compartilhar a primeira página com o editorial, a tirinha insinua que esta nova publicação trata de feminismo com leveza e, mais ainda, trata de um tema que interessa a todas as mulheres, não apenas as feministas: o trabalho doméstico. Simone de Beauvoir, uma das teóricas que inspirou o pensamento feminista da década de 1960, destacava a repetição, a

\footnotetext{
5 - Oi, querida, foi tudo bem lá no serviço? - Oi... Foi um dia duro... - Bom chegar em casa... Tou exuasto! - Eu também. - Ahhh... Me faz ai uma limonada? E o jantar, vai demorar? - Já vai já! - Que qui tem de sobremesa? Traz ai o café! - Tá fazendo a minha marmita de amanhã? Capricha nela, a de hoje tava uma droga! Puxa vida, criatura, ainda não acabou de lavar a louça?! O mundo tá perdido, olhai essas notícias... as mulheres tão com tudo, são umas folgadas e ainda vem com esse tal de movimento feminista... Qual é? Afinal, o que mais que vocês querem na vida?
} 
monotonia e a invisibilidade do trabalho doméstico e o fato das meninas serem condicionadas desde a tenra idade a esse exercício, um exercício em que o tempo é marcado pela água que ferve, pelo bolo que assa. Para a filósofa, a mulher estaria presa a um trabalho que não dá sentido à vida, um fazer secundário (2009, p. 446). É dando protagonismo a esse fazer que o jornal foi inaugurado.

Nós Mulheres foi fundado em 1976, por estudantes, acadêmicas e exiladas que retornaram ao Brasil após experiências com o feminismo estrangeiro. Ele defendia a autonomia do movimento, criticando severamente o aparelhismo e a tutela, rejeitava, portanto, a dupla militância em partidos políticos e organizações de esquerda, embora tenha sido um jornal aliado às demandas da esquerda (TELES e LEITE, 2013, p. 61). Para Amelinha Teles e Rosalina Leite, as tirinhas do Nós Mulheres são um fenômeno marcante, principalmente pela raridade das mulheres nesse meio (2013, p. 63). Cabe destacar que os outros jornais, especialmente o Brasil Mulher, que as referidas autoras foram integrantes, não tinham foco no uso do humor gráfico, ou mesmo de uma linguagem humorada, apesar de fazerem uso de carges, cartuns e quadrinhos, principalmente para a formação de base.

Desde seu primeiro número o jornal afirmou-se feminista e tratou de temas tabu como sexualidade, aborto e controle de natalidade, ao mesmo tempo que trazia para o centro do debate mulheres operárias, da periferia. Em um tempo de amadurecimento do feminismo no Brasil, Amelinha Teles e Rosalina Leite apontam que 22\% das matérias do Nós Mulheres versava sobre feminismo (2013, p. 103). Nós Mulheres buscava, portanto, articular uma visão de mundo que aliasse esquerda e feminismo, rejeitando a forma da política institucional. Eleni Varikas, em uma ampla reflexão sobre a relação entre privado e público no pensamento feminista, aponta:

Oriundo mais freqüentemente da esquerda extraparlamentar, com a qual mantinha laços estreitos, ainda que problemáticos e conflituosos, o movimento feminista, na maioria dos países da Europa Ocidental, partilhava amplamente da desconfiança da política eleitoralista, visando mais uma transformação das estruturas sociais do que uma política institucional. Mas a sua desconfiança da "política" ia muito além da visão desta esquerda. Ela se estendia à própria política da esquerda, às suas práticas de poder, às suas estruturas hierárquicas e, conseqüentemente, à validade de seu projeto político. Afirmando que o pessoal é político, não subestimava as estruturas e as instituições em proveito de uma transformação da vida cotidiana, assim como não se mantinha fora do político, em um "alhures" inocente, fantasmado. Esta afirmação insistia, ao contrário, sobre o caráter estrutural da dominação expresso nas relações da vida cotidiana, dominação cujo caráter sistemático tinha sido precisamente obscurecido, como se fosse o produto de situações pessoais. Não se tratava de escolher entre mudar as 
"mentalidades" e mudar as "instituições", pois esta "escolha" implica numa concepção do privado e do público que as feministas denunciavam precisamente como uma mistificação. Tratava-se sobretudo de mostrar que a dominação era ao mesmo tempo oculta e assegurada através de poderosas instituições como a família, a heterossexualidade institucionalizada, a divisão e a estrutura sexuada do trabalho e do emprego (VARIKAS, 1996, p. 66).

A autora destaca o esforço feminista na transformação da sociedade que não viria por vias eleitorais, mas sim de mudanças estruturais, uma vez que "Entrar no domínio da política, servir-se de suas regras, ainda que para combatê-la, é tornar-se seu auxiliar” (VARIKAS, 1996, p. 64). Tal desconfiança não seria fruto apenas da visão desta esquerda, mas também da própria política de esquerda, baseada em práticas de poder e estruturas hierárquicas que pouco se relacionam com a ideia básica de transformação. O mote "o pessoal é político" articula-se exatamente a essa noção revolucionária de política e do político, uma vez que, através dele, percebia-se o papel das estruturas e das instituições para a transformação da vida cotidiana, este lugar de protagonismo das mulheres e que ocupa integralmente o primeiro editorial do Nós Mulheres. Denunciando a mistificação do privado e do público, as feministas da segunda metade do século XX apontaram a importância do privado para a manutenção de estruturas e instituições produtoras de desigualdade e injustiça, permitiram, assim, a construção de uma ideia (re)inventada de político.

Conscientes desses perigos, as integrantes do Nós Mulheres defenderam um feminismo autônomo e, a época de sua fundação, recusaram a possibilidade de se unirem ao jornal Brasil Mulher, sabidamente defensor de uma dupla militância (TELES e LEITE, 2013, p. 83). Em função do fato de muitas terem tido experências no exterior é possível supôr que o feminismo autônomo ganhou força, uma vez que as marcas da esquerda no feminismo brasileiro são inegáveis. Maria Lygia Quartim de Moraes, integrante do Nós Mulheres, afirma que foi a distância com organizações e partidos de esquerda que permitiu que o jornal tomasse caminhos novos (TELES e LEITE, 2013, p. 170), exatamente o caminho do "o pessoal é político" que demandava uma crítica profunda às estruturas e instituições e não apenas aos agentes da política no fazer político.

No encalço da tentativa de promover um feminismo autônomo, as integrantes do Nós Mulheres procuraram inovar em termos de linguagem. Se a imprensa alternativa como um todo, principalmente dos partidos e organizações de esquerda, fazia uso de uma linguagem bastante "dura", o jornal aqui explorado focou na construção de textos "leves", o que demandava o uso do humor gráfico como ferramenta. Na estreia da coluna de humor 
publicada no número 4, de março-abril de 1977, em texto intitulado O Humor de Nós

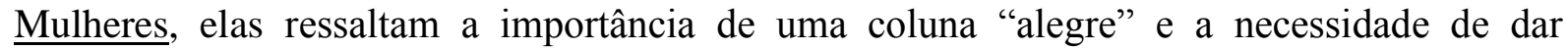
visibilidade aos cartunistas brasileiros. Segundo o texto, entre eles há elas.

O nosso objetivo é criar uma página de humor dentro do nosso jornal, continua, e, obviamente, alegre embora nem sempre o humor seja alegre. Os cartunistas brasileiros são excelente (sic), mas devido ao mercado estreito e solapado pelo similar extrangeiro (sic), em concorrência francamente desleal ("cobra preço de banana") não tem tido muitas oportunidades de explorar seu potencial, fundamental na criação de uma cultura num país como este nosso; daí que, quantos mais páginas, revistas, livros de humor brasileiro, do povo brasileiro, melhor. Bom, dentre os conhecidos humoristas brasileiros, existem mulheres cujo trabalho de alto nível, colecionamos para iniciar esta série. Comecemos com Wilde Weber, que nos contará sua experiência, já que pioneira (Nós Mulheres, 1977, p. 9).

A apresentação da coluna é bastante conciliadora e em nenhum momento é citada a hostilidade do campo do humor à produção de mulheres. Ricky Goodwin, em texto que visa apresentar a produção gráfica do humor no Brasil entre 1950 e 2000, ignora completamente a produção de mulheres - incluida a produção de Ciça, conhecida nacionalmente, que publicou por anos na Folha de S. Paulo - e afirma que, apesar de não haver mulheres no meio, os homens criaram bons personagens femininos, “[...] amplamente favoráveis às mulheres", como Rê Bordosa de Angeli e Radical Chic de Miguel Paiva (2011, p. 552) ${ }^{6}$. Apesar de negar o debate, a coluna apresenta um humor aliado à luta das mulheres e, na sequência, traz um relato de uma cartunista mulher, Wilde Weber. Compondo a coluna cinco charges assinadas por mulheres e uma tirinha de autoria de Ciça.

\footnotetext{
${ }^{6}$ A maioria dos estudos que procuram construir enciclopédias, dicionários e ontologias dos quadrinhos ou do humor gráfico brasileiro, ignoram ou desconhecem quase que absolutamente a produção de mulheres. Cartunistas como Lila, Cahu, Célia, Eva que publicam nos jornais feministas são citadas apenas em pesquisas que tem como foco a produção de mulheres.
} 


\section{Figura 2}

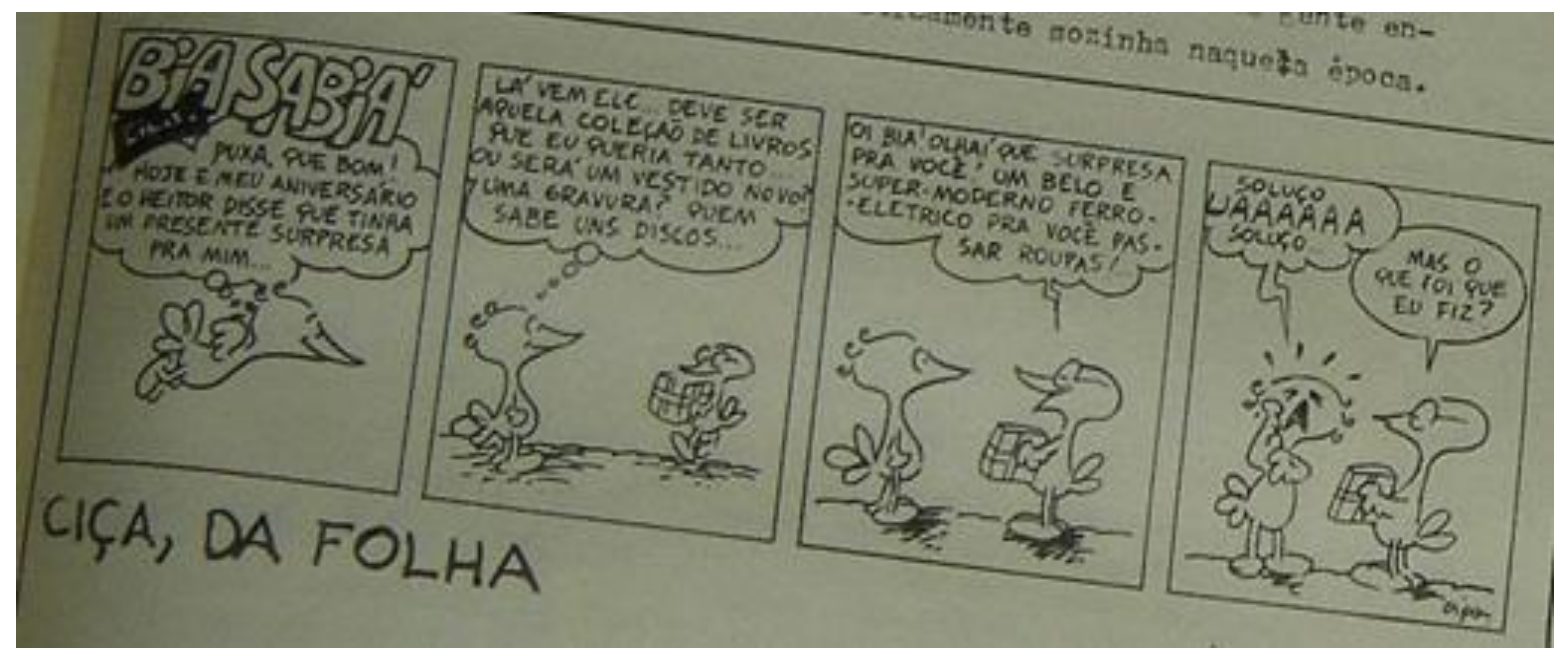

Fonte: CIÇA. Nós Mulheres. São Paulo, março-abril de 1977, Número 4, p. $9^{7}$.

Bia Sabiá, novamente, protagoniza uma cena cotidiana com Heitor. Ao contrário da tirinha anterior, em que ela desaparece dando vez aos pedidos do companheiro, nesta ela tem voz em todos os quadros. No primeiro sua voz é de expectativa diante de seu aniversário e da espera pelo presente. No segundo a expectativa aumenta e os presentes se materializam em sua mente: Vestido? Gravura? Discos? No terceiro quadro uma Bia incrédula é presenteada com um ferro-elétrico. No quarto sua voz é soluço e choro.

Bia Sabiá representa a mulher trabalhadora, casada, com filhos, o que significa que ela lida com uma dupla jornada protagonizada por pequenos passarinhos e o passarinho macho, Heitor. Respeitando a promessa do editorial número 1, as agruras vividas pelas mulheres no espaço doméstico continuam figurando nas páginas do jornal. Bia, ao ser reduzida à sua condição de mãe, frustra-se como frustram-se muitas mulheres. Ciça, ao tratar do tema com leveza e simplicidade, utilizando uma família de pássaros, aponta que a entrada maciça das mulheres no mercado de trabalho não significou uma mudança estrutural das relações privadas.

O lugar estratégico reservado desde o princípio pelo pensamento da emancipação das mulheres à "revolução nos costumes conjugais", faz do privado doméstico, do [oikos] o local privilegiado do político no duplo sentido que tinha esta palavra na aurora da modernidade, o de produto da ação humana e o de produto de uma relação de força. Mas ao mesmo

\footnotetext{
7 - Puxa, que bom! Hoje é meu aniversário e o Heitor disse que tinha um presente surpresa pra mim... La vem ele... Deve ser aquela coleção de livros que eu queria tanto... Ou será um vestido novo? Uma gravura? Quem sabe uns discos?... - Oi Bia! Olhaí que surpresa pra você. Um belo e super moderno ferro elétrico para você passar roupas! - Soluço... Uaaaaaa... Soluço... - Mas o que foi que eu fiz?
} 
tempo, situa a luta das mulheres nos antípodas do político, já que o oiko é ao mesmo tempo a condição e o oposto do político, é o local onde se domesticam as paixões e suas instigadoras principais, a serviço da comunidade. Produto desta domesticação, a feminilidade em geral, a castidade e a devoção materna tornam-se os meios de aprendizagem da lealdade, da reciprocidade, os instrumentos de regulação da paixão dos homens, a serviço da comunidade (VARIKAS, 1996, p. 63).

Para Eleni Varikas o privado é lugar privilegiado de contestação dos costumes, logo o lugar do político. O pessoal e o privado são, portanto, produto da ação humana, forma fundamental da relação de força. O humor político de Ciça, tendo uma perspectiva feminista é, nesse sentido, situado no privado e não nos gabinetes escuros do fazer político. A feminilidade seria, exatamente, o resultado dessa ação e dessa relação. Bia Sabiá não existe enquanto sujeito, Bia existe enquanto mulher que passa roupas na tirinha anterior. Bia existe como mulher que cozinha, atende o marido e lava louças na tirinha do primeiro número de Nós Mulheres. Simone de Beauvoir afirmava que ambos os sexos - homens e mulheres nunca estiveram em pé de igualdade no casamento: o homem é, socialmente, um indivíduo autônomo e, antes de tudo, produtor, o que justifica sua existência. A mulher é um meio, uma espécie de escrava ou vassala da família (2009, p. 408). É sobre essa mulher que Nós Mulheres discute em suas páginas, é essa mulher que Bia Sabiá representa.

Nós Mulheres, ao enfocar temas até então considerados tabus na sociedade, como aborto, sexualidade, ou seja, ao eleger o mote "o pessoal é político" como gerador de sua prática narrativa, gerou discussões fundamentais para um feminismo que, no Brasil, via-se em constante conflito com as esquerdas, uma vez que foi nas esquerdas que ele encontrou espaço para emergir, mas foi também entre as esquerdas que ele encontrou resistência para existir de maneira efetivamente transformadora. Ainda na discussão sobre o caráter político da vida considerada privada, as integrantes do jornal, talvez, tenham feito uso de um assunto que interessa a todas as mulheres para abrir caminhos de discussão. Explorando a questão do trabalho doméstico que provoca empatia imediata em todas as mulheres, Nós Mulheres procurou construir uma identificação instantânea entre mulheres que poderiam ser separadas por questões de classe. É importante observar que a discussão sobre raça, ou mesmo sobre os privilégios da branquitude, foi negligenciada no editorial inaugural. Mesmo reconhecendo que há mulheres ricas que contratam o serviço de outras mulheres, não se problematiza o fato desse trabalho ser desempenhado, em sua maioria, por mulheres negras e pobres ${ }^{8}$. Apesar de

\footnotetext{
8 bell hooks, referindo-se à realidade estadunidense, aponta o medo e a raiva que atravessam as relações entre empregadas negras e patroas brancas (2017, p. 147).
} 
não negar a discussão sobre racismo, os jornais feministas, como um todo, não evidenciam debates que problematizem a branquitude e seus privilégios.

A elevação do debate sobre trabalho doméstico para a ordem do político, aliada à perspectiva de que o fazer político feminista é oriundo da desestruturação das barreiras entre privado e público, passou inegavelmente pela uso do humor. As tirinhas de Ciça, articuladas a entrevistas, matérias e textos acadêmicos que denunciavam a condição das mulheres de escravas do lar, traziam a leveza e a pedagogia que apenas o humor pode promover.

\section{HUMOR GRÁFICO FEMINISTA E CIÇA}

"Será que as donas de casa da vida real desfazem em risos seus sonhos e seu desespero?” perguntou Betty Friedan (1971, p. 52). Autora de obra considerada uma das principais inspirações para a revolta das mulheres estadunidenses nos anos 1960, Betty Friedan dedicou algumas linhas de Mística Feminina à rejeição do que ela chama de humor doméstico, uma apropriação da ideia do privado inscrita no campo do humor e uma oposição ao humor político. Para ela, rir das agruras da vida privada de donas de casa é mais um efeito da mística. Levando em consideração a discussão inicial sobre humor político e o teor doméstico do humor gráfico de Ciça, poderíamos, então, nomear de humor doméstico a produção de Ciça? Não, porque não devemos perder de vista a ideia de que o "pessoal é político" e que a dicotomia privado e público serve à expulsão das mulheres do espaço público e à desvalorização do espaço privado. Não cabe reduzir o humor de Ciça à ideia de humor doméstico porque ele não é uma forma de rir de si mesma, angariando o riso e a simpatia dos homens, característica de um humor auto-depreciativo. Ciça produz um humor gráfico feminista que se inscreve no campo do político, na medida em que rompe barreiras que visam a separação entre privado e público e desestabiliza estruturas, exatamente o que um humor revolucionário deve fazer.

Umberto Eco aponta o humor como forma de enfraquecer os limites por dentro, um movimento de libertação, ele nos lembra da lei que não temos razão de obedecer (2011, p.8). O humor gráfico feminista de Ciça, personalizado aqui pela personagem Bia Sabiá, é uma lembrança repetida e constante de estruturas e instituições que atuam diretamente na desvalorização das mulheres e a tudo que a elas é relacionado, como o doméstico. Ciça, em entrevista, declarou: “O humor mostra não como as coisas devem ser, mas como as coisas não devem ser" (2018, no prelo). 


\section{Figura 3}

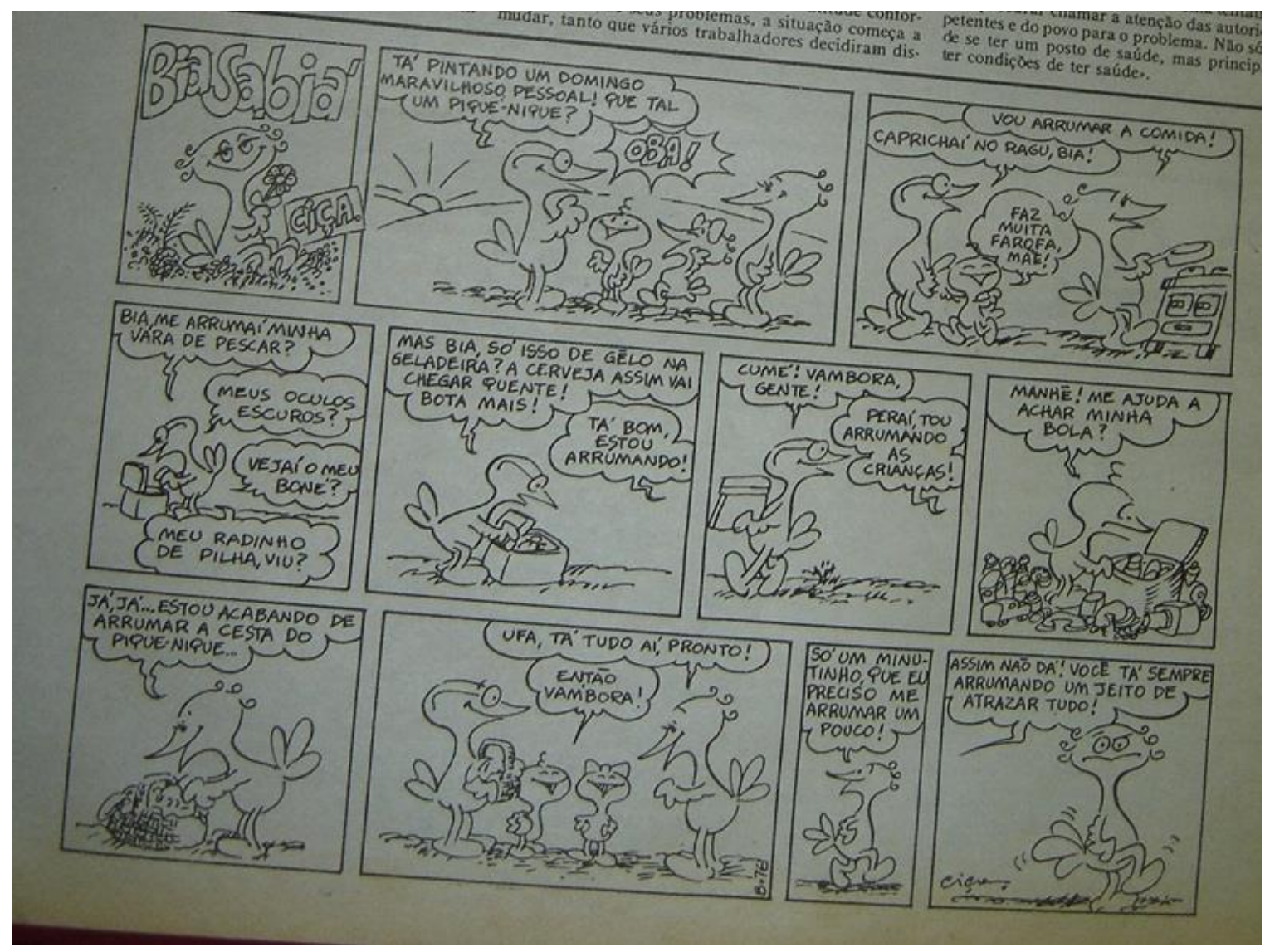

Fonte: CIÇA. Nós Mulheres. São Paulo, setembro-outubro de 1976, Número 2, p. $3^{9}$.

Em tirinha do número 2 Bia protagoniza um domingo ensolarado com a família. O sol no horizonte do primeiro quadro aponta que é dia de piquenique. Com excitação, o companheiro de Ciça e os dois filhos celebram o dia de diversão e descanso. Nos quadros subsequentes, um festival de imperativos lançados à Bia emerge: "caprichaí", "faz muita farofa”, “arrumaí”, "vejaí”. A eles Bia responde: “tá bom”, "peraí”. Finalizada a arrumação da cesta de piquenique e de - quase - todos os membros da família, Bia pede "só um minutinho", porque precisa se arrumar. O protesto de Heitor reverbera no último quadro: Bia Sabiá está atrasando o dia de diversão e descanso. Na tirinha, encenada por todos os membros da família, Heitor, mais uma vez, assume o papel do homem que não reconhece a existência da companheira para além da figura de mãe e dona de casa. Heitor é um personagem leve, não

\footnotetext{
9 - Tá pintando um domingo maravilhoso, pessoal! Que tal um pique-nique? - Oba! - Vou arrumar a comida! Caprichai no ragu, Bia! - Faz muita farofa, mãe! - Bia, me arrumaí minha vara de pescar! Meus óculos escuros? Vejaí meu boné? Meu radinho de pilha, viu? Mas Bia, só isso de gelo na geladeira? A cerveja assim vai chegar quente! Bota mais! - Tá bom, estou arrumando! - Cumé! Vambora, gente! - Peraí, tou arrumando as crianças! Manhê! Me ajuda a achar minha bola? - Já, já... Estou acabando de arrumar a cesta de pique-nique... Ufa, tá tudo ai, pronto! - Então vambora! - Só um minutinho que eu preciso me arrumar um pouco! - Assim não dá! Você tá arrumando um jeito de atrazar tudo!
} 
gera respulsa, mas indignação em função de representar o controle masculino do espaço doméstico.

\begin{abstract}
A família sob controle masculino fazia do espaço privado doméstico um espaço de "tirania", um espaço de "privação de direitos". Privação dos direitos civis e políticos que retirava de uma metade do gênero humano a independência necessária para participar, não da gestão de uma comunidade instituída de uma vez por todas sem seu consentimento, mas da própria definição do conteúdo e das regras da vida em comum (VARIKAS, 1996, p. $61)$.
\end{abstract}

Eleni Varikas, explorando a redefinição moderna de família, aponta como a família, ao contrário do Estado, se instituiu como lugar de prevalência de autoridade masculina, reforçando a ideia de um soberano. Nesse prisma o espaço privado constroi-se como espaço de tirania e privação de direitos para as mulheres, além da privação de direitos civis e políticos que, mesmo diante de revoluções, se manteve. Lynn Hunt aponta que em todas as cartas de direitos humanos fruto das revoluções francesa e estadunidense, as mulheres permaneceram excluídas da condição de sujeitos de direitos (2009, p. 150), cenário que mudaria apenas no final do século XIX e início do XX com a luta por direitos civis, especialmente o voto. Além da negação de direitos "públicos", Eleni Varikas destaca que também na vida em comum, às mulheres cabia o consentimento de regras que não eram estabelecidas por elas. Bia Sabiá, na sua resignação que combina um semblante revoltado e choro, apresenta com humor a tristeza da vida doméstica, o desespero da dona de casa que, para Betty Friedan, não pode ser objeto de riso.

O elemento da tristeza, talvez, seja um dos itens que separa definitivamente o humor gráfico feminista de Ciça do humor doméstico criticado por Betty Friedan, já que não se trata de rir de sua situação para continuar lidando com ela, a exemplo do que oferta uma das elaborações de Freud (2012). A tristeza originada pela descoberta da verdade é, também, a tristeza que provoca o riso. Vale retomar trecho da apresentação da estreia da coluna de humor, no Nós Mulheres número 4 de 1977: “O nosso objetivo é criar uma página de humor dentro do nosso jornal, contínua, e, obviamente, alegre embora nem sempre o humor seja alegre" (Nós Mulheres, 1977, p. 9). O reconhecimento de que o humor com perspectiva feminista pode ter um destino nem sempre alegre é condição fundamental para compreensão do humor gráfico de Ciça, já que ele se funda em uma premissa subversiva. Não se trata de rir das donas de casa, ou mesmo rir dos homens, trata-se de um riso revelador. 
Eco afirma que um dos efeitos desse outro humor, o humor que não se baseia na violência e no ridículo, é um riso triste: "Nós sorrimos porque nos sentimos tristes por temos descobertos, por apenas um momento, a verdade" (2011, p. 8). O choro e o semblante de frustração de Bia é, nesse sentido, o momento de descoberta da verdade. Entretanto, Regina Barreca relembra que contar uma história, uma piada, desenhar uma tirinha significa controlar a versão dessa mesma história, piada e tirinha, significa rir ao invés de chorar (1991, p. 153). Mesmo que a figura de Bia Sabiá, através dos traços de Ciça, assuma uma modalidade de riso que leva, ao final, a um sentimento de tristeza, é importante pensarmos que assumir o lugar na produção do humor é, também, um ato de poder. Fazer alguém rir é assumir uma posição de poder (BARRECA, 1991, p. 18-19) e, no campo que se constituiu como masculino, reconhecer a tripla subversão de Ciça é fundamental. Ela, assim como outras, subverte: porque é mulher produzindo humor gráfico; porque contrói um humor contra-hegemônio que desafia a norma e não a reforça; porque explora as barreiras entre pessoal e público para (re)inventar a ideia de humor/político, produzindo, assim, humor gráfico feminista.

De acordo com Janet Bing e Joanne Scheibman o humor é uma forma de comunicação ambivalente, mas há uma modalidade de humor que apresenta caráter subversivo, um humor que desafia o status quo e coloca em suspensão uma determinada situação ou estereótipo, ofertando uma alternativa à realidade estabelecida (2014, p. 13). É esse o humor gráfico produzido por Ciça e por outras mulheres que publicavam na imprensa feminista brasileira nos anos 1970 e 1980. Ao enfocar em um humor anti-"político", a partir da ideia de que "o pessoal é político", Ciça apropriou-se do privado, do cotidiano, do pessoal para pontuar como o político atravessa e marca o espaço privado. Mary Douglas aponta a piada, o que poderíamos entender como humor, como um anti-rito, na medida em que ele desorganiza a norma (1991, p. 102-103). Ciça, com sua família de pássaros, não ri do dia a dia doméstico de Bia, ela acentua a injustiça da situação vivida pelas mulheres, ela questiona a norma. $\mathrm{O}$ recurso dos animais e a simplicidade das situações demonstra, ainda, as intenções pedagógicas da cartunista.

Eu acho o humor didático, sem ser didático [...] Eu acho o humor uma dádiva. O humor é sempre contra, ele é sempre contra alguma coisa. Contanto que não seja contra o outro, rir da desgraça alheia. Em alemão tem até tem uma palavra pra isso, o prazer de ver o outro sofrer: "schadenfreude". Isso eu acho horrível, mas você mostrar como aquela atitude, aquela coisa [que não é] harmoniosa, que ela teria que ser diferente, isso eu acho didático, sem ser didático. (2018, no prelo) 
Ciça defende uma definição de humor que escapa a um grande número de conceitos que afirmam o humor como perpetuador de estereótipos e produtor de violência. Para a cartunista o humor é contra a norma, ele é pedagógico e sugere alternativas ao mundo como ele é. Uma das formas de insinuar esse caráter didático é refletir sobre o uso de animais. Inge Thomas aponta que o surgimento dos comics, nos Estados Unidos, teve como uma tendência o uso de animais para refletir sobre as excentricidades humanas (1990, p. 11). Para além de integrar uma tendência, Ciça encontrou nessa forma de representação um meio de criticar a estrutura familiar e o espaço doméstico, sem produzir um humor que atacasse pessoalmente os homens. A inocência de Heitor é prova disso. O companheiro de Bia Sabiá, mesmo representante do masculino no ambiente doméstico, é tratado quase que com carinho, mesmo quando ele mostra suas piores facetas.

\section{Figura 4}

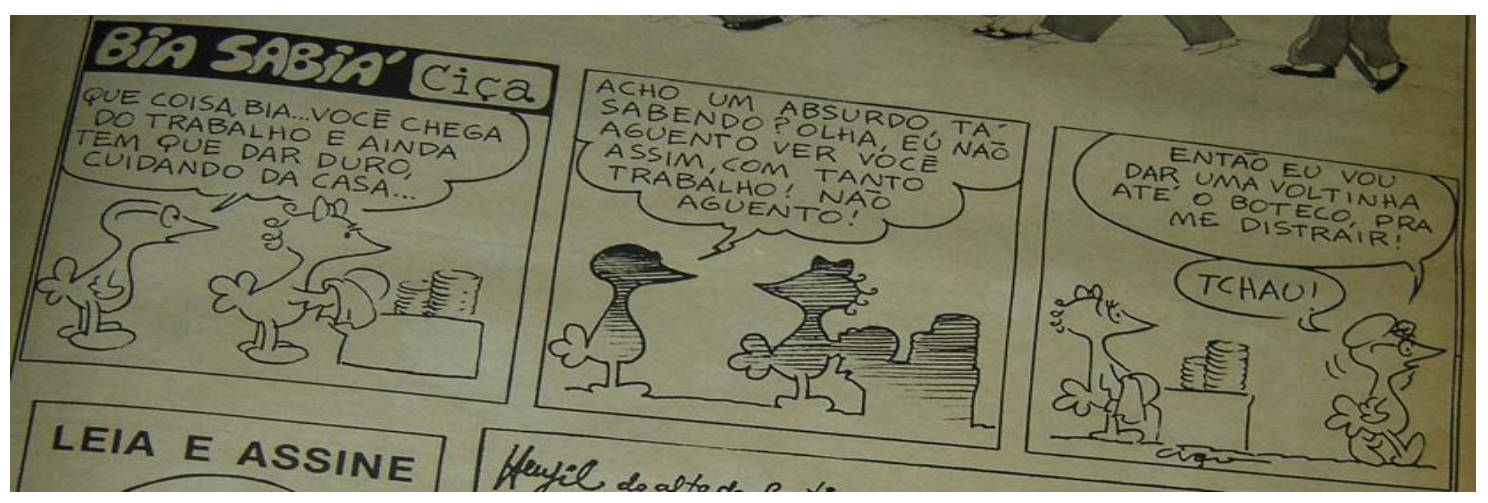

Fonte: CIÇA. Nós Mulheres. São Paulo, junho-julho de 1977, Número 5, p. $15^{10}$.

$\mathrm{Na}$ tirinha em destaque, Heitor, em um lapso de consciência, expressa simpatia em relação à dupla jornada de Bia, reconhecendo que, mesmo depois de um dia duro de trabalho, ela ainda precisa cuidar da casa. Com a indignação aumentando por essa situação injusta, o companheiro de umas das principais personagens de Ciça afirma que "não aguenta" ver Bia assim. No auge de sua revolta Heitor coloca um chapéu, um grande símbolo do espaço público, e parte para "o boteco", ele precisa se distrair da injustiça e da sobrecarga de trabalho que assola seu lar e sua companheira. Ele parte e deixa Bia para trás. Ela observa sua indignação e partida com olhos arregalados. Heitor sabe onde repousa o justo, mas não está disposto à persegui-lo.

\footnotetext{
10 - Que coisa, Bia... Você chega do trabalho e ainda tem que dar duro, cuidando da casa... Eu acho um absurdo, tá sabendo? Eu não aguento ver você assim, com tanto trabalho. Eu não aguento! Então eu vou dar uma voltinha até o boteco, pra me distrair. Tchau!
} 
Ora, o acesso das mulheres ao estatuto de sujeito individual supõe escapar não apenas das relações simbióticas da família mas de todas as "falsas" lealdades, inclusive aquelas ligadas "a seu sexo". E a única bússola para distinguir as "verdadeiras" das "falsas" lealdades é a procura do justo. (VARIKAS, 1996, p. 79)

Para Eleni Varikas, e para a cartunista Ciça, o reconhecimento da desigualdade estabelecida na família e no assim chamado mundo público é, talvez, a forma primeira de construção de justiça entre homens e mulheres. Esse reconhecimento, definitivamente, não é solitário e tem relação direta com "o pessoal é político" do anos 1960, ou seja, com a necessidade de construção dos sujeitos do feminismo, e com as bases do humor.

Regina Barreca, explorando o mito da falta de senso de humor das mulheres, que foi construído por muitos estudiosos e, principalmente, pela psicanálise, aponta a experiência coletiva das mulheres que riem juntas (1991, p. 8). O riso, resultado do humor, depende do reconhecimento de uma situação. É apenas reconhecendo as referências que somos capazes de acompanhar uma ideia elaborada a partir do humor. Para o humor funcionar, ele precisa de cumplicidade, de uma base de experiência - particular - compartilhada (BARRECA, 1991, p. 53). É essa base que, 40 anos depois da publicação das tiras protagonizadas por Bia, permite que os traços de Ciça provoquem riso, sorriso e/ou uma reflexão hoje. Rir junto é como integrar um clube (BARRECA, 1991, p. 85).

Tendo o humor sido construído no masculino - o clube dos homens seria o humor como categoria universal -, não apenas em termos de sujeitos, mas como paradigma, uma vez que fazer rir invoca poder, historicamente associado ao masculino, o humor gráfico de Ciça aponta as múltiplas possibilidades do humor gráfico produzido com perspectiva feminista, ao acionar a desestabilização do privado e do público, do pessoal e do político. Ao redefinir o político, à luz dos debates feministas, Ciça classificou a possibilidade de liberdade, pensando que a capacidade de liberdade depende da distância crítica e da desconfiança frente ao poder. Essa liberdade desafia, exatamente, as divisões fundadoras do político: privado e público, pessoal e político, feminilidade pré-política e masculinidade política, virtude feminina e virtude cívica (VARIKAS, 1996, p. 66). Nesse lógica, não há nada mais político do que o humor gráfico feminista de Ciça. 


\section{CONSIDERAÇÕES FINAIS}

O campo de estudos do humor, mesmo quando problematizado por disciplinas atentas às desigualdades de representação, como a história, foi contruído e tem se mantido articulado a um paradigma masculino que serve perfeitamente à definição de humor político uma vez que, grosso modo: "as mulheres estão para o espaço privado assim como os homens estão para o espaço público”. Tal dicotomia, definidora não apenas das relações sociais, avança no campo teórico para estabelecer a relação entre público-político e privado-pessoal, insinuando a existência das mulheres à margem do domínio que rege a sociedade. Essa elaboração, portanto, tende a esvaziar o conteúdo político do humor produzido com perspectiva feminista a partir de argumento comum: as mulheres deixam suas obras serem consumidas por suas vidas (PERROT, 2007).

Tal visão permite a afirmação da existência de uma escrita feminina, uma arte feminina, um humor feminino. Sendo a escrita, a arte e o humor, em sua essência, masculinos - sem precisar dizê-lo - toda a produção intelectual de mulheres seria, nesse sentido, marcada por suas experiências de vida - consideradas privadas, pessoais -, produção vista com desconfiança por não se relacionar com o público - e com o político. Na emergência dos feminismos da segunda metade do século XX, inspirados e produtores da ideia de "o pessoal é político", as mulheres inauguraram a possibilidade franca e aberta de questionar tais dicotomias afetando, assim, as possibilidades de produção de um humor gráfico político com perspectiva feminista que trabalha nas fronteiras entre privado e público, já que o pessoal é político.

No Brasil essa discussão ganhou várias formas e uma delas é evidenciada pelo Nós Mulheres. Buscando contruir um feminismo autonômo, apesar de sua relação com a esquerda, e na tentativa de construção de uma linguagem "outra" que não a explorada pela imprensa feminista do período, o jornal procurou, através do uso do humor gráfico, criticar e desestabilizar estruturas e instituições. O trabalho doméstico, sem dúvida, é tema estratégico para elaboração dessa reflexão.

Ao apontar a insistência da desigualdade e da injustiça no ambiente doméstico através do humor gráfico feminista de Ciça, Nós Mulheres procurou angariar a opinião das leitoras via reconhecimento e identificação de uma situação vivenciada por todas. O humor gráfico feminista de Ciça, nessa discussão, tem papel fundamental na medida em que executa dois movimentos distintos e relacionados: borra as fronteiras que procuram separar o privado do 
público, ressaltando o teor político do que é costumeiramente considerado pessoal; e faz uso de um humor subversivo, gerador de desconforto, visando a transformação e inscrevendo, assim, o político no pessoal e vice-versa. Tais movimentos permitem o vislumbre da (re)invenção do político que atinge a definição tradicional de humor político e as linguagens possíveis para essa (re)invenção protagonizada pelo principal mote dos feminismos de 1960. Bia Sabiá, em “o pessoal é político”, (re)inventou o político no humor gráfico publicado no Nós Mulheres e, hoje, obriga-nos a (re)visitar nossas ideias sobre humor.

\section{FONTES}

Nós Mulheres. São Paulo. Número 1 ao 8, 1976-1978.

\section{REFERÊNCIAS BIBLIOGRÁFICAS}

BARRECA, Regina. They used to call me snow white... but I drifted. Women's strategie use of humor. Penguin Book's: USA, 1991.

BEAUVOIR, Simone. O segundo sexo. Rio de Janeiro: Nova Fronteira, 2009.

BING, Janet, e SCHEIBMAN, Joanne. Blended Spaces as Subversive Feminist Humor. In: CHIARO, Delia; BACCOLINI, Raffaella (ed.). Gender and Humor: Interdisciplinary and international perspectives. New York and London: Routledge, 2014, pp. 13-29.

CARDOSO, Elizabeth. Imprensa feminista brasileira pós-1974. Dissertação de Mestrado defendida na Escola de Comunicações e Artes da Universidade de São Paulo, 2004.

CIÇA. "O humor mostra... como as coisas não devem ser": entrevista com a cartunista Ciça. Revista Estudos Feministas, 2018. No prelo.

DOUGLAS, Mary. Implicit Meanings: Essays in Anthropology. New York: Routledge, 1991.

DUDDEN, Arthur P. The Record of Political Humor. In: DUDDEN, Arthur Power. (ed). American Humor. Oxford University Press, England, 1987.

ECO, Umberto; IVANOVV, V.V e RECTOR, Monica. Carnival! Approachs to Semiotic. Berlin, DEU: Walter de Gruyter, 2011.

FREUD, Sigmund. The joke and its relation to the unconscious. Penguin Book's: USA, 2002.

FRIEDAN, Betty. Mística Feminina: Petrópolis: Editora Vozes, 1971.

GOODWIN, Ricky. A monovisão dos estereótipos no desenho de humor contemporâneo. In: LUSTOSA, Isabel (Orgs.). Imprensa, Humor e Caricatura: a questão dos estereótipos culturais. Belo Horizonte: Editora UFMG, 2011, pp. 535-555. 
HUNT, Lynn. A invenção dos Direitos Humanos: uma história. São Paulo: Cia das Letras, 2009.

HENFIL. Como se faz humor político. São Paulo: Kuarup, 2014.

HOOKS, Bell. Ensinando a transgredir: educação como prática de liberdade. São Paulo: Editora Martins Fontes, 2017.

INGE, Thomas M. Comic as Culture. University Press of Mississipi, 1990.

PERROT, Michelle. Minha História das Mulheres. São Paulo: Contexto, 2007.

SOIHET, Rachel. Preconceitos nas charges de $O$ Pasquim: mulheres e a luta pelo controle do corpo. In: Artcultura, Uberlândia, v. 9. n. 14, jan-.jun. 2007. p. 39-53.

TELES, Amelinha; LEITE, Rosalina Santa Cruz. Da Guerrilha à Imprensa Feminista. A construção do Feminismo pós-luta armada no Brasil (1975-198). São Paulo: Intermeios, 2013.

VARIKAS, Eleni. O pessoal é político: desventuras de uma promessa subversiva. In: Tempo, Rio de Janeiro, vol. 2, n 3, 1996, pp. 59-80.

Recebido em: 28/05/2018 Aprovado em: 27/07/2018 